\title{
Planning and Conducting Internal Audit Missions at The Public Procurement Department Level Within a Contracting Authority
}

\author{
Camelia Mădălina BELDIMAN ${ }^{\star}$
}

\begin{tabular}{l}
\hline \multicolumn{1}{c}{ A R T I C L E I N F O } \\
\hline Article history: \\
Accepted March 2021 \\
Available online May 2021 \\
\hline JEL Classification \\
H83 \\
Keywords: \\
Internal public audit, Audit \\
missions, Proposed objectives, \\
Public funds or public patrimony, \\
Implementation of \\
recommendations
\end{tabular}

A B S T R A C T

This paper aims to highlight the role of public internal audit in a public entity and the importance of conducting audit missions aimed at achieving the objectives proposed by the efficiency and effectiveness of risk management, adding value to the institution. The main objective of the public internal audit is to contribute to the improvement of the activity of public entities, to evaluate and increase the efficiency and effectiveness of the management system based on risk management, internal control and efficiency of the act of managing public funds. Internal audit is an important activity in public administration, which has evolved over time according to the needs of society, being governed by the International Institute of Internal Audit, having regulated a code of ethics and general rules of an imperative nature.

(C) 2021 EAI. All rights reserved.

\section{Introduction}

By planning and carrying out audits regularly we seek to examine the actions of financial effects on public funds or public property, in terms of compliance set of principles, procedural and methodological rules that are applied and whose main objective is ensuring the regularity of procedures and operations with the regulatory framework.

The planning and implementation of these missions mainly concern the comparison of reality with the established reference system. The main objective of performance audit missions is to evaluate the performance of the public entity in the use of public funds, comply with the principles of economy, efficiency and effectiveness and provide the upper management with an independent point of view on achieving the desired results, as well as recommendations on ways and means of increasing their performance.

The system audit mission is an in-depth assessment of the management and internal control systems, to determine whether they work economically, effectively and efficiently, to identify deficiencies and make recommendations for their correction. The system audit involves an in-depth analysis of the public entity's competences of inputs, processes and results and seeks to obtain answers on how the system has been designed and implemented.

The general methodology of the assurance missions implies, according to the present norms, the following stages: the preparation of the internal public audit mission, the on-site intervention, the reporting of the public internal audit activity, the follow-up of the recommendations.

\subsection{Internal Audit Definition}

In 1999, the U.S. Institute of Internal Auditors (I.I.A.) issued a new definition of internal audit, as follows: internal audit is an independent and objective activity, which gives an organization assurance on the degree of control it has over operations, guides it to improve them, and helps to add value. The internal audit helps this organization to achieve its objectives, evaluating, through a systematic and methodical approach, its risk management, control and management processes, and making proposals to strengthen their effectiveness.

In Law no. 672/2002 regarding the internal public audit in Romania, the definition given by the I.I.A. is adopted, in 1999.

From the definitions presented we can draw the following ideas:

- the internal audit is an independent activity (reporting must be done to a hierarchical level that 
allows it to fulfill its responsibilities) and objective (the internal auditor must have an impartial and uninfluenced attitude, must avoid conflicts of interest);

- it is an insurance activity (assurance given to the management regarding the functioning of processes / activities) and counseling (consultancy to identify obstacles that prevent the proper conduct of processes, establish causes, determine consequences, and present solutions to reduce them; facilitate understanding of certain information);

- it is an activity that results in an added value for the entity in which it is exercised (an improvement of the activity);

- the internal audit systematically and methodically addresses the processes of risk management, control and governance of the company.

From the above results the triple role that the internal audit fulfills in the life of an entity:

- advises management: internal auditors have the role of advising, assisting, recommending, providing decision support to managers at all hierarchical levels; they do not make decisions, the decision belongs to those advised or to those who received the recommendations, the internal audit being only how managers are ensured by the proper functioning and effectiveness of the internal control that falls under their responsibility;

- helps employees: the role of internal auditors is not to establish culprits and sanctions but to identify the weaknesses of the internal control system as well as the associated risks that they have to communicate to the managers involved in the audited activities; internal auditors will never mention guilty persons in internal audit reports but will only point out the shortcomings and risks identified; the decisions to correct the deviations or to eliminate the risks are the responsibility of the managers;

- independence and objectivity of the internal auditor: independence allows the auditor to judge impartially and without prejudice what is essential for the proper conduct of the audit work. In this regard, the position of the audit department within the entity (distinct under the direct subordination of the entity manager) is important. Objectivity is ensured when internal auditors have an impartial and unbiased attitude and avoid conflicts of interest.

\section{Audit at The Level of The Public Procurement Department Within a Contracting Authority}

The contracting authority (public institution) has established to accomplish its specific activities, a specialized department for public procurements. The main specific legal norms are:

- Law no. 98/2016 on public procurement;

- GD 395/2016 for the approval of the methodological norms for the application of the provisions regarding the award of the public procurement contract / framework agreement from Law no. 98/2016 on public procurement;

- Orders and instructions of the National Agency for Public Procurement;

- ANI instructions on conflict of interest.

\subsection{Control Environment}

Staff employed in the department. All employees have higher education in fields such as: economic, technical, legal. At the level of the institution there is a Code of Ethics and Integrity of Employees.

All employees have become aware of the Code of Ethics and Integrity of Employees which establishes rules of ethical conduct in the performance of duties, applicable to both management and executive staff.

The employees, after studying and mastering the Code, prepared a table with the staff within the Department confirming that they took note of the provisions of the Code of Ethics and Integrity approved by the Order of the head of the Contracting Authority (CA).

The staff are informed of the specific documents regarding the mission, the functions, the attributions of the entity, the internal regulations, and the job descriptions. Following the communication, the table of the personnel within the Service was considered, which took note of the provisions of the Internal Regulations of the CA approved by the Order of the head of the Contracting Authority (CA).

The job descriptions are elaborated or updated and considered by the job holders. They are updated according to the changes from the specific legislation.

At the compartment level, sensitive functions were identified and inventoried. For each procurement procedure, the persons with decision position are updated and presented to the potential bidders.

There are several control measures to ensure the reduction of risks associated with sensitive positions: each member appointed to the evaluation committees signs, immediately after the deadline for submission of tenders, a declaration of confidentiality and impartiality. From the departments with which the public procurement staff collaborates (legal, technical, computerization) at least two persons are appointed within the evaluation commission (member and reserve member) for the eventual situations in which the titular member must be replaced. 
Within the contracting authority, the periodic evaluation of the employees' performances is performed. This is done through the individual professional performance evaluation reports. These reports also identify training programs for the next evaluation period. The staff participates in courses and trainings as the legislation changes very often. At the institution level, therefore, also within the department, there is the possibility of delegating attributions through the Order of the AC leader. At the same time, when submitting a request for leave, the person who takes over the attributions of the one who leaves is also mentioned.

\subsection{Risk Evaluation} evaluated.

At the department level, the risks related to the objectives or activities must be identified and Objectives:

Thus, the following objectives and risks were identified.

1. Increasing the bidders' confidence in the correctness of the bidding analysis and evaluation process;

2. Decreasing the time of a procedure;

3. Market prospecting to carry out the acquisition;

4. Preparation of the annual public procurement strategy. Risks:

1. Increase the number of complaints;

2. Failure to complete the purchase in a timely manner;

3. Improper award of the procurement contract;

4. Late preparation of the Annual Public Procurement Strategy.

For each risk identified during the audit mission, the possible causes must be pursued:

1. Insufficient detail the requirements demanded to be met by the specifications drawn up by structure required to perform such acquisitions;

2. Unjustified requirements related to the object of the contract;

3. Delay in the presentation of the documents necessary for the initiation of the acquisition;

4. Improper establishment of the estimated value of the contract;

5. Establishing inappropriate technical requirements in the specifications / report;

6. Failure to present in due time by the services the reports of necessity based on which the Annual Program of public procurements at the level of the institution is drawn up.

At the department level, a performance monitoring and reporting system is established, based on the indicators associated with the specific objectives:

1. The degree of admission of appeals from the total appeals filed, calculated as the ratio between the number of appeals admitted and the total number of appeals filed x 100 . The level of indicators was established as follows: below 30\% - high performance, between 30-50\% - average performance, over $50 \%$ - low performance;

2. Number of procedures canceled due to authority fault over the total number of procedures assigned in the current year, calculated as the ratio between the Number of canceled procedures / Total procedures initiated in the current year x 100. The level of indicators was set as follows: below $10 \%$ high performance, between 10-20\% - medium performance, over 20\% - low performance. The procedures in which there were no bidders registered in the system as potential interested economic agents are not considered;

3. Average duration of a procedure (4 months works, 3 months Supply / Services) calculated as a ratio between the number of procedures whose tender evaluation period did not exceed the average duration of a procedure / total procedures x 100. The level of indicators was established thus: below $65 \%$ - low performance, between 65-75\% - medium performance, over 75\% - high performance;

4. Annual public procurement plan - All public procurement contracts / framework agreements that the contracting authority intends to award during the year. Preparation in the time indicated by the legal norms means high performance. Exceeding the time is considered low performance.

\subsection{Control Activities}

At the compartment level, the documents are signed by the head of the compartment. The manager helps employees necessary to perform the tasks outlined. The manager verifies the activity of the employees regarding the accomplishment of the drawn-up tasks, and coordinates the documents elaborated by the personnel within the department. At the same time, in accordance with the provisions of GEO no. 98/2017 based on a selection methodology, ex-ante control is performed by NAPP (National Agency for Public Procurement) through SEAP.

\subsection{Information and Communication}

The types of information, their content, frequency, sources and recipients were established, so that the management and the execution staff, by receiving and transmitting the information, can fulfill their 
service tasks. The inventory of documents by categories used in the entity was established; list of documents of public interest; archival nomenclature. Procedures are applied for the registration, dispatch, drafting, classification, filing, protection and archiving of internal and external documents, as appropriate. At the level of the institution, it was implemented a document management system - Electronic Register. Through it, the documents inside the institution can be followed, the responsible persons are designated, and a response time can be established.

For the publicity of the procurement procedures, the Electronic Public Procurement System (SEAP) is used, respectively the e-licitatie.ro platform. Participation announcements, data sheets, specifications and all other documents related to a public procurement are published here. Also here are published the requests for clarifications and the answers to the requests for clarifications, the errata type announcements, the communications regarding the result of the procedure, the eventual appeals and the decisions issued by National Council for Solving Complaints (CNSC) to those appeals.

For the relations with the press or other interested persons, the communication channel represented by the spokesperson of the institution is used.

\subsection{Monitoring}

The head of the department performs, annually, the self-evaluation operation of the managerial internal control system by completing the self-evaluation questionnaire and sending it to the Internal Control Department in December. The answers in the self-assessment questionnaire are proven with appropriate supporting documents.

The audit department verifies, by survey, the procedures that led to the non-fulfillment of the level of performance indicators and always those that led to damages (payment of damages, court costs or that brought even intangible damages to the authority to introduce measures correction).

\section{Case Study}

Within a project with European financing, with an implementation duration of 18 months, having as object the increase of the energetic performance of a building, the service with technical attributions sent the report of necessity and the specifications related to the procedure. These documents include indications about the estimated value of the acquisition, documentation for approving the intervention works (DALI) as well as other technical requirements as well as the duration of the contract execution - 12 months.

Based on the submitted documentation, the public procurement department started the award procedure: the announcement of participation in SEAP was published, all the necessary documents were uploaded. Until the deadline for submission of bids, due to the complexity of the responses to the requests for clarification of potential bidders, the bid submission period was extended by 10 days. Following new clarifications requested by potential bidders, it was found that, due to some legislative changes that have occurred recently, a series of opinions issued by various entities had to be presented in the Terms of Reference. In this situation, the contracting authority was forced to cancel the procurement procedure left in SEAP. After a series of changes to the documentation, the procedure was resumed after about 20 days, being finally assigned.

The audit team, as the procedure was canceled but, several economic agents showed interest for it, checked the conduct in terms of compliance with internal procedures. The team found that the technical documentation submitted had not been updated, with DALI including unrevised prices. In this way, the technical procedure indicated by the designer could not be implemented at the value estimated by the technical department. It was necessary to revise DALI at the level of market prices and to integrate in the Specifications the requests for clarifications addressed by the potential bidders and appropriated by the contracting authority.

The audit team concluded that, due to the lack of clarity of the technical documents and the nonupdating of the documentation, the procurement procedure was delayed by about 45 days. Given that the procurement procedure was carried out within a project with European funding that had a well-defined implementation period, the contracting authority could have been put in the situation of not meeting the deadlines, this could lead to a financial penalties or loss of funding. At the same time, based on the outdated documentation, the contracting authority had to launch a procurement that had an erroneously estimated value. However, the contracting authority had the possibility, with the agreement of the ministry managing the funds allocated to the respective financing axis, to transfer amounts from one project line to another, to increase the amount allocated to the procurement of works, to avoid increasing ineligible amounts (i.e., borne by own budget).

\section{Conclusions}

Following the verifications performed, the audit team, in addition to the findings, decided to formulate proposals to improve the activity within the institution, as follows: when receiving the reports based on which the procurement strategy will be prepared at the authority level and when which is approved 
the annual procurement plan at the level of the contracting authority, the public procurement department will issue a notification to each service / compartment / office, etc., reminding the need to verify / update the data presented. At the same time, the technical department will be required a mechanism for monitoring the technical documentation through which they will no longer be transmitted without the approval of the legal service for the verification from the point of view of updating the documents according to the legal provisions. At the same time, the audit team proposes the creation of a team / office that, before submitting applications for European funds, but also after signing the financing agreements to perform a control of compliance of technical documentation with the requirements of funding guidelines to avoid financial corrections.

\section{References}

1. GD 395/2016 for the approval of the methodological norms for the application of the provisions regarding the award of the public procurement contract / framework agreement from Law no. 98/2016 on public procurement published in the Official Gazette no. 430 with subsequent amendments and completions

2. Ghiță, M. and Sprânceană M. (2006), "Auditul intern în sistemul public" (Internal audit in the public system), Editura Tribuna Economică, București.

3. Law no. 672/2002 regarding the internal public audit, published in the Official Gazette no. 953 of December 24th, 2002, with subsequent amendments and completions.

4. Law no. 98/2016 regarding public procurement, published in the Official Gazette no. 390 of May 23rd, 2016, with subsequent amendments and completions.

5. Oprea, I. (2010), “Control și audit intern - suport de curs pentru masterat" (Internal control and audit - course support for master's degree), Universitatea Creștină Dimitrie Cantemir, Cluj-Napoca. 